\title{
Natural Antioxidants as Efficient Preventive Agents Against Mycotoxicoses: Case of Citrinin Mycotoxin
}

\author{
Chayma Bouaziz $^{1 *}$, Amal Salah ${ }^{1,2}$, Chiraz Zaied ${ }^{1,3}$ and Salwa Abid-Essefi ${ }^{1}$ \\ ${ }^{1}$ Faculty of Dental Medicine, Monastir University, Laboratory of Research on Biologically Compatible Compounds, Tunisia \\ ${ }^{2}$ Faculty of Sciences of Bizerte, Carthage University, Tunisia \\ ${ }^{3}$ Higher Institute of Biotechnology of Beja, Jendouba University, Tunisia
}

*Corresponding author: Chayma Bouaziz, Faculty of Dental Medicine, Monastir University, Laboratory of Research on Biologically

Compatible Compounds, Tunisia

\section{ARTICLE INFO}

Received: 䶕 January 22, 2020

Published: 幽 January 31, 2020

Citation: Chayma Bouaziz, Amal Salah, Chiraz Zaied, Salwa Abid-Essefi. Natural Antioxidants as Efficient Preventive Agents Against Mycotoxicoses: Case of Citrinin Mycotoxin. Biomed J Sci \& Tech Res 25(2)2020. BJSTR. MS.ID.004167.

Keywords: Mycotoxin; Citrinin; Cinnamon; Fenugreek; Mitochondrial Potential Drop; Oxidative Stress

\section{ABSTRACT}

Cinnamon (Cinnamomum zeylanicum) and fenugreek (Trigonella foenum-græcum) are two widespread used condiments with many health benefits. Their addition to savoury dishes might help minimizing the deleterious effects of natural food contaminants. Mycotoxins are among the most naturally occuring food contaminants. They are products of the secondary metabolism of molds belonging maily to the genera Aspergillus, Penicillium and Fusarium. These mycotoxins can grow on the plant in the field or during storage and are potentially toxic to humans and animals. Among these mycotoxins, Citrinin (CTN), produced by different species of Penicillium and Aspergillus, is likely to contaminate certain foodstuffs. CTN is recognized as a pro-oxidant molecule causing oxidative stress which affects many cellular organelles such as mitochondria. Therefore, fighting the oxidative processes induced by CTN would help to reduce the cellular damages and the subsequent toxicity more effectively. In this work, in Human Colorectal Cells (HCT116), we have studied the preventive effects of aqueous extracts of two medicinal plants: Cinnamon (CAN) and Fenugreek (FEN) as regarded to CTN toxicity. We have shown that CTN induced a decrease in HCT116 cells viability concomitantly with a mitochondrial transmembrane potential $(\Delta \psi)$ drop. The pretreatment of HCT116 cells in culture with CAN or FEN have diminished the mortality induced by CTN concomitantly with a clear restoration of the $\Delta \psi$ potential when compared to cells treated with CTN alone. These results suggest that use of condiments can be persuaded as a preventive strategy against oxidative damage induced by food contaminants.

Abbreviations: CAN: Cinnamon; FEN: Fenugreek; CTN: Citrinin; $\Delta \psi$ : Mitochondrial Potential; HCT116: Human Colorectal Cells; ROS: Reactive Oxygen Species; DPPH: 2,2-Diphényl-1-Picrylhydrazyl; FDA: Fluorescein Diacetate; DiOC6(3): 3,3'-Dihexyloxacarbocyanine Iodide; $\mu \mathrm{g}$ EAG/mg: Extract Micrograms of Gallic Acid Equivalent Per Milligram of Extract; $\mu \mathrm{g}$ EQ / mg of extract: Micrograms of Quercetin Equivalent Per Milligram of Extract; $\mu \mathrm{g}$ EAT / mg extract: Micrograms of Tannic Acid Equivalent Per Milligram of Extract; RAS: Radical Scavenging Activity; A: Absorbance; EC50: 50\% Effective Concentration; IC50: Inhibitory Concentration 50\%.

\section{Introduction}

Molds are widely used in the agro-food industry where they participate, under controlled conditions, in the processing of raw food materials into products of high added value (cheese, etc.). However, aside from this beneficial aspect, some molds can become harmful by altering not only the organoleptic and nutritional properties of food but also their health incidence by synthesizing secondary metabolites (mycotoxins) causing deleterious health effects in the organisms. According to the United Nations Food and Agriculture Organization about $25 \%$ of food is contaminated with mycotoxins. This scourge affects commodities at all stages of 
the food chain, leading to considerable economic damage for the various actors in the sectors concerned. The health consequences are multiple: lower yields and grain quality, lower weight of poultry and livestock, increased susceptibility to infections due to weakened immune defences, increased mortality of livestock, leading to considerable economic losses [1].

Nowadays, mycotoxins and the specific pathologies induced are of worldwide interest and represent serious economic and public health problems. They are known to exert a broad variety of biological effects due to the great variability of their chemical structures. The mycotoxin citrinin (CTN), mainly produced by species of the genus Penicillium and Aspergillus, has particularly aroused our interest. It is recognized mainly by its nephrotoxic, hepatotoxic, immunotoxic and teratogenic effects in animals [2-4]. Cytotoxicity and reactive oxygen species (ROS) generation are the major mechanisms involved in mycotoxins toxicity. ROS are highly reactive molecules due to the presence of unpaired electrons. Moreover, the cell can tolerate a small to moderate amount of oxidative stress by producing antioxidant molecules to counteract the excess oxidants.

Hence, living organisms maintain a permanent balance between the damage caused by the oxidizing molecules and their repair process. Oxidative stress appears when this balance is disrupted [5]. Facing these food risks, preventive strategies limiting the occurrence of these contaminations aim to decontaminate food contaminated with mycotoxins. Meanwhile, the usual food processes (cooking, freeze-drying and freezing) can in general only partially destroy the mycotoxins present in foods [6-8]. Enhancing the antioxidant defences of the body by ensuring a healthy diet, balanced and rich in antioxidants (vitamins, trace elements, carotenoids, polyphenols ...) is essential to avoid this imbalance. These food antioxidants are found mainly in fruits and vegetables. Indeed, several studies have shown the crucial role of a diet rich in fruits and vegetables in the protection against cancer and the risk of cardiovascular accidents [9].

In the same way, these plants also exploited in traditional medicine were proved to be an important source of antioxidant compounds. In this context, we were interested in two medicinal plants: (i) Fenugreek, Trigonella foenum-græcum $L$ which is a small leguminous plant, belonging to the family "Fabaceae". The leaves of fenugreek are used in salads and seeds are used as a spice. It is one of the oldest medicinal and culinary plants in the history (ii) Cinnamon, Cinnamomum zeylanicum, belonging to the family of "Lauracea", is supplied by the fragrant bark of the cinnamon, small exotic tree whose most widespread species grows in the island of Ceylon. Cinnamon is widely used as condiment in both savoury and sweet dishes. Using a variety of experiments, we have tried to evaluate the antioxidant activity of the aqueous extracts of fenugreek (FEN) and cinnamon (CIN) grains. We have further tested their ability to reduce the cellular damage caused by CTN

\section{Material and Methods}

\section{Preparation of the Aqueous Extracts of Fenugreek and Cinnamon}

The aqueous extracts were prepared according to the protocol proposed by Haoula [10]. Briefly, 3g of unmilled fenugreek seeds are weighed and soaked in $100 \mathrm{ml}$ of distilled water in a shaker at $25^{\circ} \mathrm{C}$ for 24 hours. The solution was filtered through a wattman paper and a filter $(0.45 \mu \mathrm{m})$. Similarly, cinnamon rinds were washed and dried for one week in ambient air. They were then cut into small pieces and ground to obtain a powder. $2.5 \mathrm{~g}$ of powder were diluted in $100 \mathrm{ml}$ of distilled water. The solution is boiled on a hot plate. The two preparations were then centrifuged. Finally, the supernatant obtained was evaporated by speed-vac. Our preparations were stored at $-20^{\circ} \mathrm{C}$.

\section{Determination of Polyphenols}

The determination of polyphenols was carried out according to the Folin-Ciocalteu method optimized by Musci and Yao [11]. Briefly, two $\mathrm{ml}$ of Na2CO3 (2\%) were added to $100 \mu \mathrm{l}$ of each test extract $(1 \mathrm{mg} / \mathrm{ml}$ ). After incubation for $2 \mathrm{~min}$ at ambient temperature, 100 $\mu \mathrm{l}$ of Folin solution (50\%) were added and the mixture was incubated for 30 min at room temperature. Finally, the optical density was determined at $765 \mathrm{~nm}$ against a blank sample containing $100 \mu \mathrm{l}$ of the solvent. The percentage of polyphenols of the fractions studied was calculated relative to the standard range of gallic acid.

\section{Determination of Flavonoids}

The determination of flavonoids in our extracts was carried out according to the method described by Zhishen and al. with a slight modification [12]. $500 \mu \mathrm{L}$ of the extract and fractions were mixed with $1.5 \mathrm{ml}$ of $99.9 \%$ ethanol, $100 \mu \mathrm{L}$ of $1 \mathrm{M}$ potassium acetate, 100 $\mu \mathrm{L}$ of $10 \%$ aluminium chloride. Then, the volume was adjusted to $2.5 \mathrm{ml}$ with distilled water. The solution was incubated for $30 \mathrm{~min}$ at room temperature and the absorbance was measured at $415 \mathrm{~nm}$ against a blank sample without the extract. The percentage of flavonoids was determined relatively to Quercetin standard curve.

\section{Determination of Tannins}

The quantification of the tannins at the level of the extracts was carried out according to Hajimahmoodi et al. with slight modification [13]. Briefly, $50 \mathrm{mg}$ of the extract were dissolved in $500 \mu \mathrm{l}$ of ethyl acetate. The solution was stirred every $10 \mathrm{~min}$. The mixture was then centrifuged for 15 minutes at $4000 \mathrm{rpm}$ and the supernatant was diluted in $1 \mathrm{ml}$ of solvent. $10 \mu \mathrm{l}$ of Folin Dennis reagent and $25 \mu \mathrm{l}$ of $7 \%(\mathrm{w} / \mathrm{v}) \mathrm{Na}_{2} \mathrm{CO}_{3}$ solution were added to $50 \mu \mathrm{l}$ of diluted supernatant. The volume is adjusted to $500 \mu \mathrm{l}$ with $\mathrm{H}_{2} \mathrm{O}$ then incubated at room temperature for one hour. Finally, the absorbance was measured at $760 \mathrm{~nm}$ as referring to a blank containing $50 \mu \mathrm{l}$ of sterile water instead of the extract. 


\section{DPPH Radical Scavenging Activity}

The DPPH assay is one of the most common assays that aim to prove the antioxidant potential of plant extracts. The scavenging activity of DPPH radical by CAN and FEN was examined by the method of Yang [14]. Volumes of $1 \mathrm{ml}$ solutions with different concentrations $(\mu \mathrm{M})$ were added to $50 \mathrm{mM}$ DPPH in ethanol. After incubation at $60^{\circ} \mathrm{C}$ for $30 \mathrm{~min}$, the absorbance $(\mathrm{A})$ of the resulting solution was determined at $517 \mathrm{~nm}$. The percentage of DPPH radical scavenging activity (RSA), was calculated using the following formula:

RSA $(\%)=$ A DPPH $-($ A sample - A control $) \times 100 / A D P P H$

\section{Measuring Cell Death Rate}

Fluorescein diacetate (FDA) fluorescent probe was used to assess cell death. After treatment with CTN (at concentrations corresponding to $\mathrm{IC} 50=150 \mu \mathrm{M}$ ) in the presence or absence of FEN or CAN at concentrations corresponding to their EC50's, the cells were incubated with $0.2 \mu \mathrm{g} / \mathrm{ml}$ of FDA for $5 \mathrm{~min}$ at $37^{\circ} \mathrm{C}$. Cell viability was then analysed by flow cytometry. The FDA is cleaved by viable cell esterases into a fluorescent product. During late events of cell death, esterases are no longer active and the FDA is not cleaved and therefore, does not fluoresce.

\section{Measurement of Mitochondrial Membrane Potential}

After incubation with CTN (at concentrations corresponding to IC $50=150 \mu \mathrm{M}$ ) in the presence or absence of FEN or CAN at concentrations corresponding to their EC50's, the cells were labelled for 30 minutes at $37^{\circ} \mathrm{C}$ with $100 \mathrm{nM}$ DiOC6(3). For each sample analyzed, the integrity of the plasma membrane is evaluated by measuring the permeability of the cells to propidium iodide $(10 \mu \mathrm{g} / \mathrm{mL}$ final), added to the sample a few minutes before the measurement in cytometry.

\section{Statistical Analysis}

Each experiment was performed separately in triplicate. Values were presented as means \pm S.D. One-way ANOVA was used to assess differences among groups followed by Dunnett's post hoc test. Differences were considered significant at $\mathrm{p}<0.05$ using Spss program.

\section{Results}

\section{Aqueous Extracts Content in Polyphenols, Flavonoids and Tannins}

Our results have shown that the aqueous FEN extract presented the highest polyphenol content which was expressed in micrograms of gallic acid equivalent per milligram of extract " $\mu \mathrm{g} E A G / m g$ extract" (10.37 $\mu \mathrm{g}$ EAG / mg). This result confirms the high content of FEN in polyphenolic substances. However, CAN has shown a lower amount of polyphenols (7.88 $\mu \mathrm{g}$ EAG / mg). Likewise, FEN has a more or less significant quantity of flavonoids which is expressed in micrograms of quercetin equivalent per milligram of extract " $\mu \mathrm{g}$ EQ / mg of extract" (4.52 $\mu \mathrm{g}$ EQ / mg) and a high amount of tannins which is expressed in micrograms of tannic acid equivalent per milligram of extract " $\mu \mathrm{g}$ EAT / mg extract" (12.05 $\mu \mathrm{g}$ EAT / mg). Meanwhile, CAN which has shown higher quantities of flavonoids (6.61 $\mu \mathrm{g} \mathrm{EQ} \mathrm{/} \mathrm{mg)} \mathrm{and} \mathrm{tannins} \mathrm{(15.12 \mu g} \mathrm{EAT} \mathrm{/} \mathrm{mg)} \mathrm{(Table} \mathrm{1).}$

Table 1: Secondary metabolites (polyphenols, flavonoids and tannins) content of aqueous extracts of Cinnamon (CAN) and Fenugreek (FEN), determined by specific colorimetric assays.

\begin{tabular}{|c|c|c|}
\hline Metabolites & Aqueous extract of CAN & Aqueous extract of FEN \\
\hline Polyphenols & $7,88 \mu \mathrm{g}$ & $10,37 \mu \mathrm{g}$ \\
\hline Flavonoïds & $6,61 \mu \mathrm{g}$ & $4,52 \mu \mathrm{g}$ \\
\hline Tanins & $15,12 \mu \mathrm{g}$ & $12,05 \mu \mathrm{g}$ \\
\hline
\end{tabular}

\section{DPPH Radical Scavenging Activity}

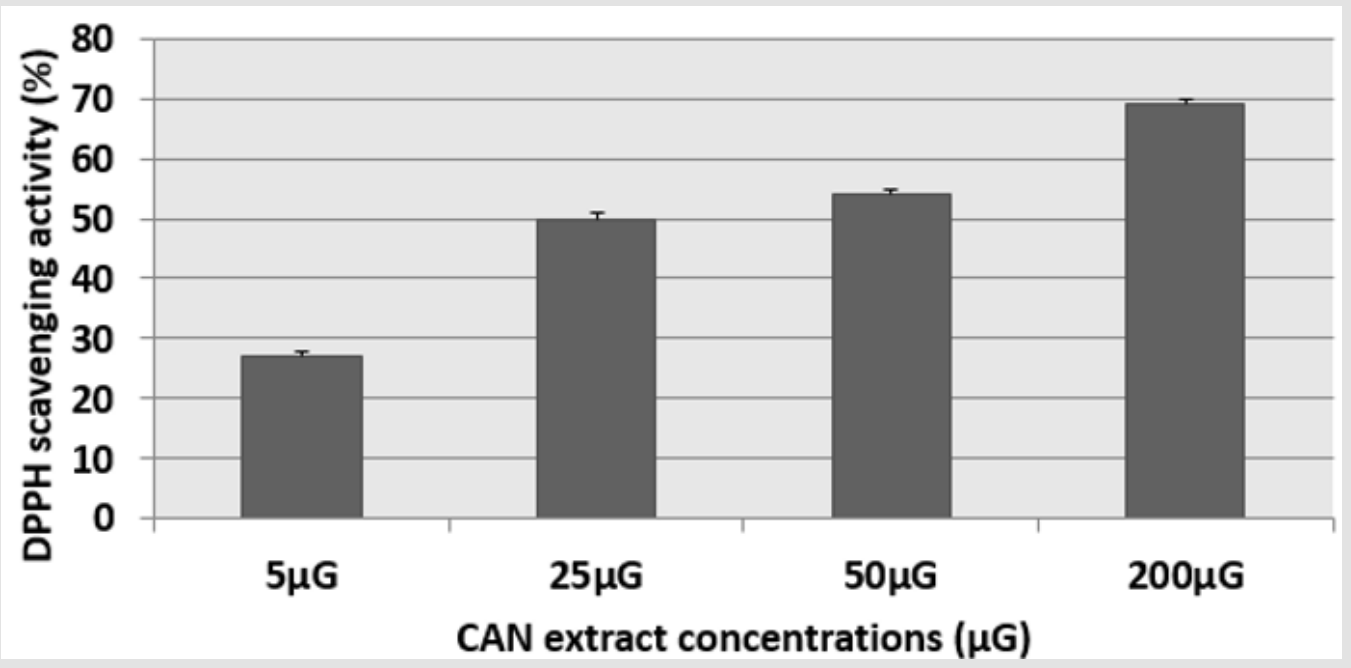

Figure 1: Percentage inhibition of the DPPH radical in the presence of different concentrations of cinnamon (CAN) extract. The corresponding EC50 determined is $25 \mu \mathrm{G}$. Results are expressed as the mean \pm SD of three independent experiments. 
The results of this test were expressed as: percentage of anti-free radical activity. They can also be expressed using the parameter EC50, which is defined as the concentration of the substrate which causes a loss of $50 \%$ of the activity of DPPH [15]. We have noticed that the different extracts have the capacity to reduce the free radical DPPH (purple in color) to the yellow radical DPPH-H in a dose-dependent manner (Figures $1 \& 2$ ). That is to say, the percentage of DPPH inhibition increased with the concentration of the extracts up to a threshold or the percentage of inhibition stabilizes with the increase in the concentration of the extracts. Indeed, for cinnamon (CAN) we have obtained an inhibition rate of $27.19 \%$, $49.38 \%, 54.38 \%$ and $68.99 \%$ respectively for the concentrations $5 \mu \mathrm{G} / \mathrm{ml}, 25 \mu \mathrm{G} / \mathrm{ml}, 50 \mu \mathrm{G} / \mathrm{ml}$ and $200 \mu \mathrm{G} / \mathrm{ml}$. Similarly for fenugreek (FEN), we have an inhibition of 31\%, 34\%, 50\% and $64 \%$ respectively for the concentrations $10 \mu \mathrm{G} / \mathrm{ml}, 25 \mu \mathrm{G} / \mathrm{ml}, 50 \mu \mathrm{G} /$ $\mathrm{ml}$ and $200 \mu \mathrm{G} / \mathrm{ml}$.

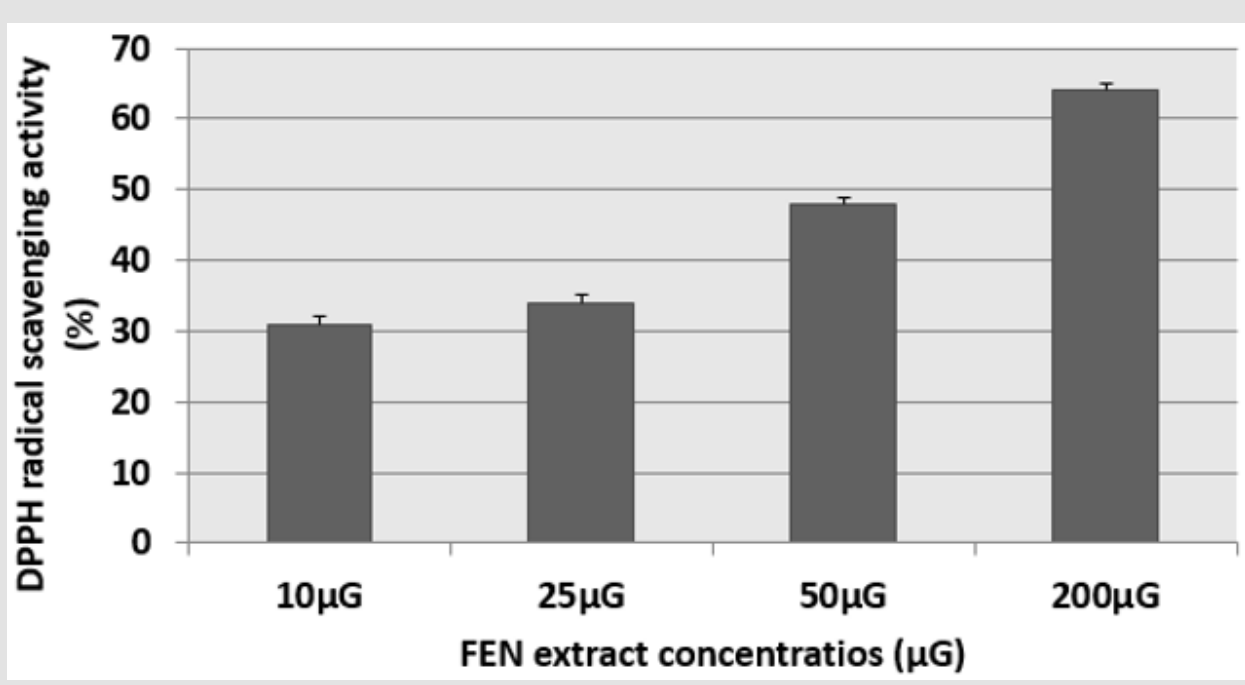

Figure 2: Percentage of inhibition of the DPPH radical in the presence of different concentrations of fenugreek (FEN) extract. The corresponding EC50 determined is $50 \mu \mathrm{G}$. Results are expressed as the mean \pm SD of three independent experiments.

Citrinin Induced Cell Mortality and Prevention by Fenugreek and Cinnamon

Pretreatment of HCT-116 cells with the aqueous extract of fenugreek at $50 \mu \mathrm{G} / \mathrm{ml}$ (EC50) and with the aqueous extract of cinnamon at $25 \mu \mathrm{G} / \mathrm{ml}$ (EC50) have shown a significant reduction in cells mortality. In fact, CAN at $25 \mu \mathrm{G} / \mathrm{ml}$ diminished citrinininduced mortality by more than $30 \%$ when compared to cells treated with CTN alone. Similarly, FEN prevented citrinin-induced mortality by approximately $30 \%$ when compared to cells treated with CTN alone (Figure 3).

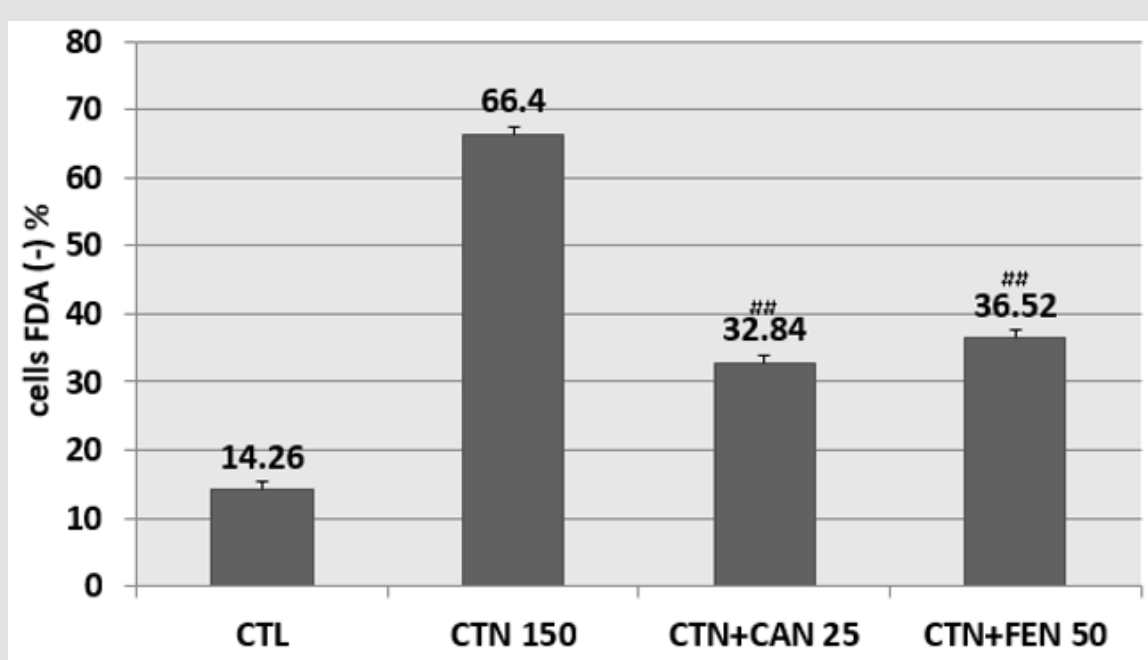

Figure 3: Percentage of inhibition of citrinin-induced mortality following pretreatment with aqueous cinnamon and fenugreek extracts. Results are expressed as the mean $\pm \mathrm{SD}$ of three independent experiments. ${ }^{*} \mathrm{P}<0.001$ vs control, \#\# P<0.05 vs CTN alone. 
Prevention of Citrinin Induced Mitochondrial Membrane

\section{Potential Drop by Cinnamon and Fenugreek}

Pre-treatment of HCT-116 cells with EC50s of cinnamon or fenugreek have shown a decrease in percentage of Dioc (-) cells. The preventive effect of cinnamon at $25 \mu \mathrm{G} / \mathrm{ml}$ against the fall in $\Delta \psi$ is attained with a prevention percentage of $50 \%$ when compared to cells treated with CTN alone. Similarly for fenugreek, also has a preventive potential which restores the mitochondrial potential of cells with CTN, the percentage of prevention is $50 \%$ compared to cells treated with CTN alone (Figure 4).

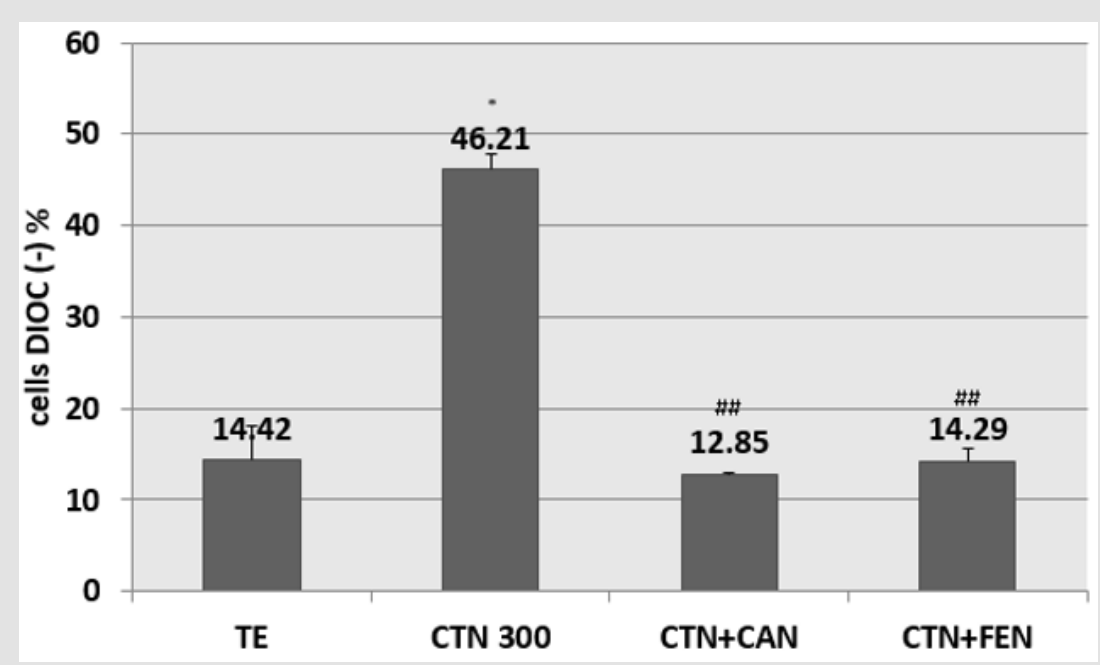

Figure 4: Percentage of inhibition of citrinin-induced mitochondrial potential drop following pretreatment with aqueous cinnamon (CAN) and fenugreek (FEN) extracts assessed by DIOC6 (3) assay. Results are expressed as the mean \pm SD of three independent experiments. * $\mathrm{P}<0.001$ vs control, \#\# $\mathrm{P}<0.05$ vs $\mathrm{CTN}$ alone.

\section{Discussion}

Since ancient times, man has used plants, either to feed or to heal himself. After many successive gropings over centuries, a first distinction has been made between edible and toxic plants. Accumulated empirical knowledge has allowed different civilizations to take plants as an essential source of medicines. Until the beginning of the 20th century, almost all drugs were of plant origin. A number of environmental pollutants are known to cause imbalance between the formation and removal of free radicals, thus leading to oxidative stress. The ensuing oxidative stress causes damage to membrane lipids, proteins and DNA. Many studies have demonstrated that CTN induced changes in oxidative status and induced free radicals generation. These free radicals are at the origin of a reaction cascade that fragments membrane lipids, and consequently contributes to the destabilization of membrane structures.

Oxidative stress is important as a direct and indirect initiator as well as a promoter of the apoptotic process which is due either to the deficiency of cellular antioxidant defence systems $[16,17]$ or to overproduction of oxygenated free radicals that exceeds their antioxidant capacity [5]. As a result, molecules with antioxidant properties can cope with stress induced by mycotoxins and restore the balance of oxidants / antioxidants. An antioxidant can be defined as any substance capable, at a relatively low concentration, of competing with other oxidizable substrates and thus retarding or preventing the oxidation of these substrates [18]. Vitamins have been tried to prevent the toxic effects of mycotoxins. Indeed, vitamins, particularly vitamin $\mathrm{E}$ which is a free radicals scavenger, has been shown to prevent the cytotoxicity of CTN, zearalenone and T-2 toxin [19]

On the other hand, the protective role of food components such as fructose chlorophylls or piperine was proved against deleterious effects of mycotoxins in general [20]. Resveratrol also showed a preventive effect against cytotoxicity and apoptosis induced by citrinin in Hep G2 cell line [21]. Even more recent studies have shown a significant preventive effect of the antioxidant-rich extract of cactus (Opuntia ficus-indica) in the protection against the genotoxicity induced by the fusarial toxin zearalenone. This was evidenced by the reduction in micronucleus induction, the decrease in the frequency of chromosomal aberrations and DNA fragmentation [22]. This extract was also effective as a hepatoprotector against the toxicity of aflatoxin B1 as demonstrated by the decrease in the level of MDA and the levels of expression of Hsp 70 and Hsp 27, as well as the decrease in expression of pro-apoptotic p53 and Bax proteins [23].

Another study has also demonstrated the efficiency of the aqueous extract of garlic (Allium sativum), with antioxidant activity, against the cytotoxicity and genotoxicity of zearalenone induced in vitro on Vero renal cells [24]. The direct use of condiments and plant extracts in cultured cells to counteract the deleterious effect of toxicants has proven its relative efficiency in our study. FEN (Trigonella foenum-græcum $L$ ) is widely used in alternative medicine. It's a common ingredient in many dishes all over the world 
and often taken as a supplement. CAN (Cinnamomum zeylanicum) is a delicious spice used in a wide variety of sweet and savoury dishes. It has been prized for its medicinal properties and has a plethora of impressive health benefits. The richness of FEN and CAN in secondary metabolites known in the literature for their important biological and pharmacological activities $[25,26]$ have incited us to test the content of the two prepared extracts FEN and CAN in antioxidants using colorimetric assays.

The distribution of secondary metabolites may change during the development of the plant. This can be linked to harsh climatic conditions (high temperature, sun exposure, drought, salinity), which stimulate the biosynthesis of secondary metabolites such as polyphenols [27]. Indeed, the phenolic content of a plant depends on a number of factors intrinsic (genetic) and extrinsic (climatic conditions, cultural practices, maturity at harvest and storage conditions) $[27,28]$. By comparing the anti-free radical activities of CAN and FEN, we can say that the percentage of inhibition of the DPPH radical in the presence of FEN is lower compared to that of CAN (Figure 1). This shows a possible correlation between the activity of the aqueous extract of FEN and its flavonoid content. The low flavonoids content of fenugreek (in comparison with CAN) is probably the cause of its lower anti-free DPPH radical activity.

Indeed, the interaction of flavonoids with many radicals has been used in several studies to determine the major elements of antioxidant activity. Because of their low redox potentials, the flavonoids (FL-OH) are thermodynamically capable of reducing oxidizing free radicals such as superoxide, peroxide, alkoxyl and hydroxyl by hydrogen transfer [29]. The anti-free radical activity has been correlated with the oxidation potential of flavonoids [30]. Moreover, the cytotoxic assays have brought an additional argument to the protective potential of FEN and CAN aqueous extracts. Pretreatment of HCT-116 cells with the aqueous extract of fenugreek at 50 $\mu \mathrm{G} / \mathrm{ml}$ (EC50) and with the aqueous extract of cinnamon at $25 \mu \mathrm{G}$ / $\mathrm{ml}$ (EC50) have shown a significant reduction in the mortality of cells as compared to those treated with CTN alone. The same effect was observed relatively to mitochondrial potential drop $\Delta \psi_{m}$ which is compromised early during stress response and a key element of ongoing cell death. Likewise this potential drop is a point of no return and it can induce cell death by apoptosis or by necrosis depending on severity of the mitochondrial damage [31,32]. The ability of cinnamon and fenugreek extracts to prevent and protect against the fall of mitochondrial potential is due to their antioxidants content such as flavonoids and polyphenols detected in both extracts (Table 1). By comparing the preventive effect of CAN and FEN, we noticed that these two extracts are capable of preventing the fall of $\Delta \psi$. These effects confirm the undeniable capacity of flavonoids to limit the production of ROS $[33,34]$. The flavonoids present on the surface of the membranes are also capable of regenerating Vitamin E, one of the essential antioxidants involved in the protection of cell membranes [35-37]. The results of these studies need to be confirmed by an in vivo study on an animal model, a model presenting all the enzymes necessary for metabolism, to better assess the level of protection of these two extracts both at the animal and at the human level.

\section{Conclusion}

On HCT-116 cells in culture, we have shown in previous reports, that CTN induced a cytotoxic effect. Indeed, it was able to inhibit cell viability, it disrupted the mitochondrial function. However, pre-treatment of cells with aqueous extracts of CAN and FEN two medicinal plants rich in flavonoids and polyphenols has counteracted these toxic effects. Both extracts were proved capable of ameliorating cell viability and restoring the $\Delta \psi$ transmembrane potential in comparison with cells treated with CTN alone which testifies the preventive effectiveness of CAN and FEN.

\section{References}

1. (1982) FAO Mycotoxin surveillance: a guideline. Prepared in Collaboration with the United Nations Environment Programme. Food Nutr 21: 1-68.

2. Frank HK (1992) Citrinin. Z Ernahrungswiss (3): 164-177.

3. Wichmann G1, Herbarth 0, Lehmann I (2002) The mycotoxins citrinin, gliotoxin, and patulin affect interferon-gamma rather than interleukin-4 production in human blood cells. Environ Toxicol 17(3): 211-218.

4. Chan WH (2008) Effects of citrinin on maturation of mouse oocytes, fertilization, and fetal development in vitro and in vivo. Toxicol Lett $180(1): 28-32$.

5. Halliwell B, Gutteridge JMC (2007) Free Radicals in Biology and Medicine. ( $4^{\text {th }}$ En.) Oxford University Press, Oxford, UK.

6. Bullerman LB, Ryu D, Jackson LS (2002) Stability of fumonisins in food processing. Adv Exp Med Biol 504: 195-204.

7. Park DL (2002) Effect of processing on aflatoxin. Adv Exp Med Biol 504: 173-179.

8. Ryu D, Jackson LS, Bullerman LB (2002) Effects of processing on zearalenone. Adv Exp Med Biol 504: 205-216.

9. Liu BH, Yu FY, Wu TS, Li SY, Su MC, et al. (2003) Evaluation of genotoxic risk and oxidative DNA damage in mammalian cells exposed to mycotoxins, patulin and citrinin. Toxicology and Applied Pharmacology 191(3): 255-263.

10. Haouala R, Hawala S, El Ayeb A, Khanfir R, Boughanmi N (2008) Aqueous and organic extracts of Trigonella foenum-graecum $\mathrm{L}$. inhibit the mycelia growth of fungi. J Environ Sci 20(12): 1453-1457.

11. Musci M, Yao S (2017) Optimization and validation of Folin-Ciocalteu method for the determination of total polyphenol content of $\mathrm{Pu}$-erh tea. Int J Food Sci Nutr 68(8): 913-918.

12. Zhishen J, Mengcheng T, Jianming W (1999) The determination of flavonoid contents in mulberry and their scavenging effects on superoxide radicals. Food Chemistry 64(4): 555-559.

13. Hajimahmoodi M, Hanifeh M, Oveisi MR, Sadeghi N (2008) Determination of total antioxidant capacity of green teas by the ferric reducing/ antioxidant power assay. Iranian J Environ Health Sci Eng 5(3): 167-172

14. Yang J, Guo J, Yuan J (2008) In vitro antioxidant properties of rutin. LWT Food Sci Technol 41(6): 1060-1066.

15. Markowicz Bastos DH, Saldanha LA, Catharino RR, Sawaya ACHF, Cunha IBS, et al. (2007) Phenolic Antioxidants Identified by ESI-MS from Yerba Maté (Ilex paraguariensis) and Green Tea (Camelia sinensis) Extracts. Molecules 12(3): 423-432. 
16. De Lamirande E, Jiang H, Zini A, Kadoma H, Gagnon C (1997) Reactive oxygen species and sperm physiology. Review of Reproduction 2(1): 4854

17. Pantano C, Reynaert NL, Van Der Vliet A, Janssen Heininger YM (2006) Redox-sensitive kinases of the nuclear factor kappaB signaling pathway. Antioxidants and redox signaling 8(9-10): 1791-1806.

18. Berger MM (2006) Nutritional manipulation of oxidative stress: review of the evidence. Nutrition Clinique et Métabolisme 20: 48-53.

19. El Golli E, Hassen W, Bouslimi A, Bouaziz C, Ladjimi MM, et al (2006) Induction of Hsp 70 in Vero cells in response to mycotoxins cytoprotection by sub-lethal heat shock and by Vitamin E. Toxicol Lett 166(2): 122-130

20. Galvano F, Piva A, Ritieni A, Galvano G (2001) Dietary strategies to counteract the effects of mycotoxins: a review. J Food Prot 64(1): 120131.

21. Chen CC, Chan WH (2009) Inhibition of citrinin-induced apoptotic biochemical signaling in human hepatoma G2 cells by resveratrol. Int J Mol Sci 10(8): 3338-3357.

22. Zorgui L, Imen AB, Yosra A, Hassen B, Wafa H (2009) The antigenotoxic activities of cactus (Opuntiaficus-indica) cladodes against the mycotoxin zearalenone in Balb/c mice: prevention of micronuclei, chromosome aberrations and DNA fragmentation. Food Chem Toxicol 47(3): 662-667.

23. Brahmi D, Bouaziz C, Ayed Y, Ben Mansour H, Zorgui L, et al. (2011) Chemopreventive effect of cactus Opuntia ficusindica on oxidative stress and genotoxicity of aflatoxin B1. Nutrition \& Metabolism 8: 73.

24. Abid Essefi S, Zaied C, Bouaziz C, Ben Salem I, Kaderi R, et al. (2011) Protective effect of aqueous extract Allium sativum against zearalenone toxicity mediated by oxidative stress. Experimental and Toxicologic Pathology 64(7-8): 689-695.

25. Edenharder R, Grunhage D (2003) Free radical scavenging abilities of flavonoids as mechanism of protection against mutagenicity induced by tert-butyl hydroperoxide or cumene hydroperoxide in Salmonella Typhimurium TA102. Mutat Res 540(1): 1-18.

26. Park KY, Jung GO, Lee KT, Choi J, Choi MY, et al. (2004) Antimutagenic activity of flavonoids from the heartwood of Rhus verniciflua. J Ethnopharmacol 90(1): 73-79.

\section{ISSN: 2574-1241}

DOI: $10.26717 /$ BJSTR.2020.25.004167

Chayma Bouaziz. Biomed J Sci \& Tech Res

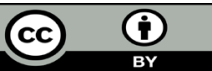

This work is licensed under Creative

Commons Attribution 4.0 License

Submission Link: https://biomedres.us/submit-manuscript.php
27. Falleh H, Ksouri R, Chaieb K, Karray Bouraoui N, Trabelsi N, et al. (2008) Phenolic composition of Cynara cardunculus L. organs, and their biological activities. C R Biologies 331: 372-379.

28. Podsedek A (2007) Natural antioxidants and antioxidant capacity of Brassica vegetables: A review. LWT 40(1): 1-11.

29. Rice Evans CA, Miller NJ, Paganga G (1996) Structure-antioxidant activity relationships of flavonoids and phenolic acids. Free Radic Biol Med 20(7): 933-956.

30. Van Acker SABE, van den Berg DJ, Tromp MNJL, Griffioen DH, van Bennekom WP, et al. (1996) Structural aspect of antioxidant ctivity of flavonoids. Free Rad Biol Med 20(3): 331-342.

31. Kroemer G, Petit P, Zamzami N, Vayssiere JL, Mignotte B (1995) The biochemistry of programmed cell death. FASEB J Off Publ Fed Am Soc Exp Biol 9(13): 1277-1287.

32. Bouaziz C, Bacha H (2010) Mitochondrial dysfunctions in response to mycotoxins: An overview. Mitochondria structure, functions and dysfunctions: 811-828.

33. Moridani MY, Pourahmad J, Bui H, Siraki A, O Brien PJ (2003) Dietary flavonoid iron complexes as cytoprotective superoxide radical scavengers. Free Radic Biol Med 34(2): 243- 253.

34. Engelmann MD, Hutcheson R, Cheng IF (2005) Stability of Ferric Complexes with 3-Hydroxyflavone (Flavonol), 5,7-Dihydroxyflavone (Chrysin), and 3',4'-Dihydroxyflavone. J Agric Food Chem 53(8): 29532960.

35. Jessup W, Rankin SM, De Whalley CV, Hoult JR, Scott J, et al. (1990) Alphatocopherol consumption during low-density-lipoprotein oxidation. Biochem J 265(2): 399-405.

36. Negre Salvayre A, Mabile L, Delchambre J, Salvayre R (1995) AlphaTocopherol, ascorbic acid, and rutin inhibit synergistically the copperpromoted LDL oxidation and the cytotoxicity of oxidized LDL to cultured endothelial cells. Biol Trace Elem Res 47(1-3): 81-91.

37. Wickramasinghe SN, Hasan R, Khalpey Z (1996) Differences in the serum levels of acetaldehyde and cytotoxic acetaldehyde-albumin complexes after the consumption of red and white wine: in vitro effects of flavonoids, vitamin E, and other dietary antioxidants on cytotoxic complexes. Alcohol Clin Exp Res 20(5): 799-803.

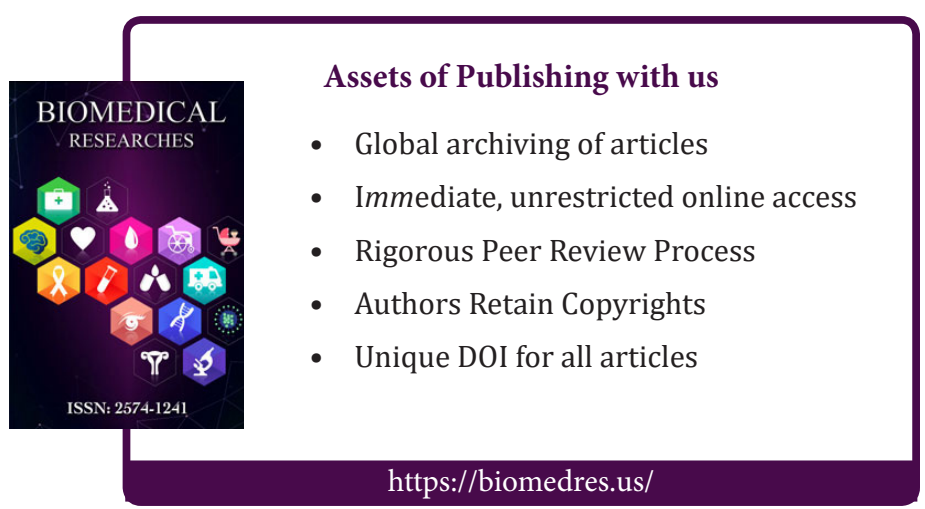

